\title{
A COMPREHENSIVE STUDY OF THE EFFECT OF HOT-DIPPING PROCESS PARAMETERS ON Sn-Sb COATING PROPERTIES FOR a-BRASS SUBSTRATE
}

\author{
Ali Barak*, Morteza Tamizifar \\ School of Metallurgy and Materials Engineering, Iran University of Science and \\ Technology, Narmak, Tehran 16846-13114, Iran
}

Received 22.10.2020

Accepted 02.01.2021

\begin{abstract}
This study's main purpose is to achieve an optimal hot-dip coating condition of Sn$\mathrm{Sb}$ for an $\alpha$-brass alloy. Therefore, the hot-dipping parameters, including pre-flux lubricants, immersion temperature, time, and withdrawal speed were investigated. $\mathrm{ZnCl}_{2}$ and $\mathrm{SnCl}_{2}$ were used as pre-flux bath additives. The temperature of the immersion bath was selected to be in the range of $250-300{ }^{\circ} \mathrm{C}$. Also, the exposing time and withdrawal speed of the specimens during the hot-dipping process were in the range of 10-60 sec and $254-1524 \mathrm{~mm} / \mathrm{min}$, respectively. Visual inspection of the coating revealed that by using $\mathrm{SnCl}_{2}$ as a pre-flux additive, high-quality smooth coating is achieved. According to the AFM result, the initial roughness value of the substrate was $450 \mathrm{~nm}$. The coating's roughness value with $\mathrm{SnCl}_{2}$ and $\mathrm{SnCl}_{2}+\mathrm{ZnCl}_{2}$ pre-fluxes were in the range of 300-500 and $700-900 \mathrm{~nm}$, respectively. Therefore, $\mathrm{ZnCl}_{2}$ pre-flux is associated with a rougher surface. Corrosion test analysis revealed that both coating condition with different prefluxes leads to increasing corrosion resistance however better improvement in corrosion behavior is accomplished by smooth coating surface. The quantitative analysis of the polarization curve revealed that the corrosion rate of the smooth coating is decreased 7 12.5 times in comparison with the substrate. According to the SEM analysis, the predominant phases which were appeared at the interface of the coating and substrate were $\mathrm{Cu}_{3} \mathrm{Sn}$ and $\mathrm{Cu}_{6} \mathrm{Sn}_{5}$. SEM analysis revealed that the $\mathrm{Cu}_{3} \mathrm{Sn}$ intermetallic compound was this first phase, which was promoted near to the substrate vicinity during the hotdipping process.
\end{abstract} SEM.

Keyword: $\alpha$-brass alloy; hot-dipping coating; polarization curve; intermetallic;

*Corresponding author: Ali Barak, Alibarak77@gmail.com 


\section{Introduction}

Brass alloys $(\mathrm{Cu}-\mathrm{Zn})$ have been regarded as commercial alloys. This alloy is one of the familiar candidates for electrical structure, pipe and valve industries due to its excellent thermal and electrical conductivity and appropriate corrosion resistance properties [1-3]. The previous studies demonstrated that the corrosion resistance of the brass alloys is severely dependent on the value of Zinc [4, 5]. As a result of dezincification, the corrosion resistance of the brass alloys was considerably dropped [69]. One practical method for protecting the corrosion behavior of engineering alloys, especially copper base alloy is coating [10]. Among different coating methods, the hotdipped method has been widely developed because of its convenience, time and costsaving issue [11]. The promoted coating has strongly protected the substrate against corrosion. The chemical composition of the coating was selected according to the working and environmental conditions [12]. Kebede et al. [13] reported a list of organic and inorganic inhibitors in order to increase the corrosion resistance of the copper base alloys. Nickel and Tin-Antimony are conventional chemical composition of the coating which is generally used for brass alloys. Previous studies demonstrated that the quality of the coating, especially in the hot-dipping technique, is directly related to the process parameters $[11,14,15]$. An appropriate coating should guarantee the free from defect, excellent adhesion and uniformity of thickness. Despite the limited studies about the quality of coating for copper-base alloy via hot-dipping process, the parameters were comprehensively investigated for other engineering alloys. For instance, the immersing time and pre-flux additives on microstructure evolution of coating for galvanized steel were studied by Deshmukh et al. [16]. It was revealed that when the exposure time is in the range of 5-10 minutes the high-quality coating is developed. In another research, hotdipping is optimized in order to obtain a high-quality coating for steel sheets [17]. According to the results of that research, it was clarified that the best immersion time and bath temperature of the hot-dipping process are 1 minute and $450{ }^{\circ} \mathrm{C}$, respectively. Also, the quality of the promoted coating is improved when the selected withdrawal speed of the specimens was in the range of $3-5 \mathrm{~m} / \mathrm{min}$. Most of the researches about the optimization of the hot-dipping process are focused on steels [18-20], aluminum [21], titanium [22], and superalloys [23, 24]. However, hot-dipping process parameters of copper-base alloys, especially $\alpha$-brass alloy have not been comprehensively investigated. Due to the significant demand for $\alpha$-brass alloy in various branches of industry, it is required to study the corrosion protection methods and especially the hot-dipping process of this alloy. One of the vital steps for industrializing $\alpha$-brass alloys is to optimize its hotdipping process parameters. Therefore, the main aim of this study is to optimize the hotdipping process of $\mathrm{Sn}-2.5 \% \mathrm{Sb}$ on $\alpha$-brass alloy and achieve a high-quality coating. The studied parameters are as follows: 1) chemical composition of the pre-flux, 2) temperature of the bath, 3) immersion time, and 4) withdrawal speed of the specimens. After optimizing the promoted coating, the corrosion properties of the alloy was evaluated. Also, the uniformity of the thickness and the appeared phases on the interface of the substrate (i.e. $\alpha$-brass) and coating (Sn-2.5\% Sb) was characterized by SEM and XRD techniques. 


\section{Experimental}

The chemical composition of the $\alpha$-brass alloy, which was used as a base metal, has been determined using OES analysis. The result revealed that the chemical composition of the base metal is $30 \% \mathrm{Zn}-70 \% \mathrm{Cu}$. The specimens with a dimension of $3 \times 6 \mathrm{~cm}^{2}$ were provided. The initial thickness of the specimens was approximately 2.5 $\mathrm{mm}$. At the first step of preparation, the surface of the specimens was properly degreased. For this purpose, the specimens were cleaned in the alkali solution under a magnet heater at the temperature of $70^{\circ} \mathrm{C}$ for 3 minutes. The chemical composition of the alkali solution was reported in table 1.

Table 1. The chemical composition of the alkali solution.

\begin{tabular}{llllll}
\hline Compound & $\mathrm{NaOH}$ & $\mathrm{Na}_{2} \mathrm{CO}_{3}$ & $\mathrm{Na}_{3} \mathrm{PO}_{4}$ & $\mathrm{Na}_{2} \mathrm{SiO}_{3}$ & Distilled waster \\
\hline Amount & $6 \mathrm{~g}$ & $8 \mathrm{~g}$ & $6 \mathrm{~g}$ & $10 \mathrm{~g}$ & $200 \mathrm{ml}$ \\
\hline
\end{tabular}

In the second step, the alkali solution components were completed wiped out from the specimens' surface via the pickling process. Hence, the specimens were completely dried at $100{ }^{\circ} \mathrm{C}$ and immediately pickled using $\mathrm{HCl}(30 \%)-\mathrm{H}_{2} \mathrm{O}(70 \%)$ solution. The pickling time was minimized in order to inhibit from pitting phenomenon. Eventually, the specimens were washed and dried at $100{ }^{\circ} \mathrm{C}$. At this step, the specimens have been ready for the hot-dipped coating process. The effect of pre-flux baths on coating quality is going to be investigated in this research. During the hot dipping process, various lubricants, including $\mathrm{SnCl}_{2}, \mathrm{ZnCl}_{2}$, and $\mathrm{NH}_{4} \mathrm{Cl}$ was added to the melting bath. Experimental results revealed that appropriate coating was achieved as a result of using $\mathrm{SnCl}_{2}$ and $\mathrm{ZnCl}_{2}$ lubricants. The chemical composition of the used pre-flux baths was reported in table 2 . The temperature of the melt bath was selected to be in the range of $250-320^{\circ} \mathrm{C}$. The exposure time and withdrawal speed of the specimens via the hot-dipping process were $254-1524 \mathrm{~mm} / \mathrm{min}$ and $10-60 \mathrm{sec}$, respectively.

Table 2. The chemical composition of the used flux.

\begin{tabular}{lll}
\hline Pre-flux baths number & The component of the flux & Pre-flux baths \\
\hline 1 & $12 \mathrm{~g} \mathrm{ZnCl}_{2}+80 \mathrm{cc}$ distilled water & $\mathrm{ZnCl}_{2}$ \\
2 & $6 \mathrm{~g} \mathrm{ZnCl}_{2}+6 \mathrm{~g} \mathrm{SnCl}_{2}+80$ cc distilled water & $\mathrm{SnCl}_{2}+\mathrm{ZnCl}_{2}$ \\
3 & $10 \mathrm{~g} \mathrm{SnCl}_{2}+80 \mathrm{cc}$ distilled water & $\mathrm{SnCl}_{2}$ \\
\hline
\end{tabular}

In the following steps after the hot-dipped coating process, the thickness of the coatings has been measured using optical microscopy (Reichert - Jung/micro-dromat $4000 \mathrm{E})$. The metallographic preparation has been fulfilled based on the conventional metallographic method. In this method, the cross-section of the specimens was prepared using $\mathrm{SiC}$ abrasive papers and mechanical polishing with alumina powder. The thickness of the specimens was measured using Clemex software. The roughness of the coating was determined using the atomic force microscopy (AFM) technique. Also, the appeared phases via hot-dipped coating process were detected using low angle $\mathrm{X}$-ray diffraction and Gazing methods (Xpert pro MPD PANalytical). Finally, the microstructure, thickness and the appeared phase in the coating were characterized using scanning electron microscopy (TESCAN, VEGA/XMU). After optimizing the hot-dipping parameters, a high-quality coating of $\mathrm{Sn}$-Sb on $\alpha$-brass base metal was achieved subsequently the corrosion behavior of the optimal coating was measured via polarization test. The 
corrosion polarization test was carried out by AutoLab PGSTAT (potentiostatgalvanostat) machine at the temperature of $25^{\circ} \mathrm{C}$. The slope of the Tafel plot has been derived using potentiostatic technique in a $3.5 \% \mathrm{NaCl}$ solution. The reference and counter electrode was $\mathrm{Ag}-\mathrm{AgCl}$ and $\mathrm{Pt}$, respectively. The dimension of the working electrode was $1 \times 1 \mathrm{~cm}^{2}$ and the corrosion test has been done on high-quality coated specimens with an area size of $1 \mathrm{~cm}^{2}$. The potential value of the solution has been measured using Cyclic Voltammetry (CV) test. The potential range and scanning rate were selected to be 0.85 $11 \mathrm{mv}$ and $0.5 \mathrm{~mW} / \mathrm{sec}$, respectively. Finally, the extracted curves have been interpreted using NOVA 17.8 software.

\section{Results and discussion}

The effect of pre-flux additives on the quality of the coating

In this section, the effect of pre-flux additives on the quality of the coating was investigated. The effect of pre-flux type on the quality of the promoted coating was visually illustrated in figure 1 . For an exact evaluation of the pre-flux effect on the coating, the other hot dipping parameters including immersion temperature, exposure time and withdrawal speed were invariable. Visual inspection of the obtained coating indicates that the quality of the coating is insufficient if the hot dipping process is performed without adding a pre-flux component (figure 1.a). The surface of the $\alpha$-brass was completely covered by the coating if $\mathrm{ZnCl}_{2}$ (figure 1.b) or $\mathrm{ZnCl}_{2}+\mathrm{SnCl}_{2}$ (figure 1.c) was used as pre-flux. However, in these conditions, the promoted coatings are rough and matte. Also, the smooth and glossy coating is achieved by using $\mathrm{SnCl}_{2}$ as a pre-flux additive (figure 1.d). Therefore, it can be declared that among the pre-fluxes which were used in this study, the best quality of the coating is accomplished via using $\mathrm{SnCl}_{2}$. In the following, the microstructure of the coating with high quality was evaluated. As can be seen in figure 2, the microstructure of the coating is including coarse dendritic solid solution phase of $\beta$-Sn (dark region) and precipitated $\mathrm{Sn}-\mathrm{Sb}$ phase (bright region).

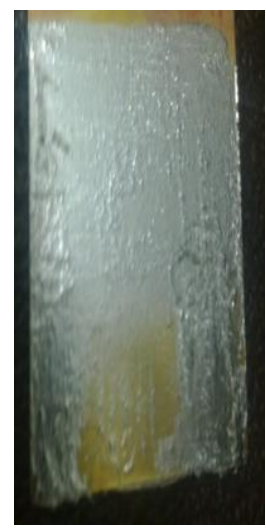

(a)

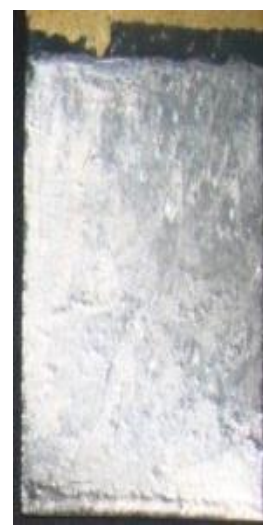

(b)

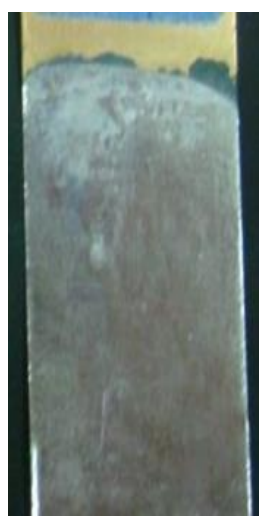

(c)

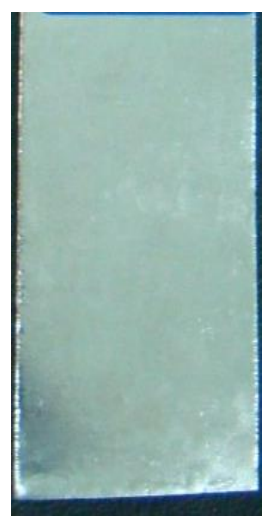

(d)

Fig. 1. The effect of pre-flux additives on the coating quality: a) without pre-flux, $b$ ) $\mathrm{ZnCl}_{2}$, c) $\mathrm{ZnCl}_{2}+\mathrm{SnCl}_{2}$, d) $\mathrm{SnCl}_{2}$. 


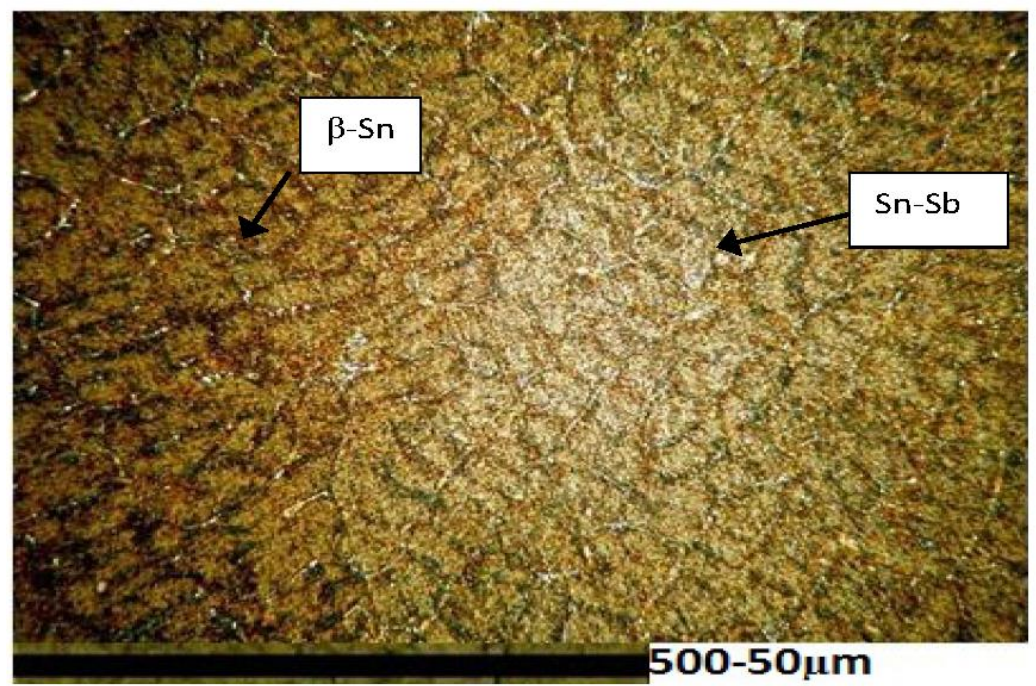

Fig. 2. The microstructure of the promoted coating with the best quality as a result of $\mathrm{SnCl}_{2}$ pre-flux.

The effect of a pre-flux component on the topography of the surface was exactly measured using atomic force microscopy (figure 3). According to the AFM results, it was revealed that the rough and smooth surface of the coating is corresponding to the $\mathrm{ZnCl}_{2}+\mathrm{SnCl}_{2}$ and $\mathrm{SnCl}_{2}$ pre-fluxes, respectively. Quantitative analysis of the surface revealed that the roughness value of the substrate (before the coating process) is approximately $431 \mathrm{~nm}$ (figure 3.a). As a result of $\mathrm{ZnCl}_{2}$ pre-flux, the roughness of the surface was increased to $917 \mathrm{~nm}$ (figure 3.b). The roughness of the surface is decreased to $549 \mathrm{~nm}$ by using $\mathrm{ZnCl}_{2}+\mathrm{SnCl}_{2}$ as pre-flux (figure 3.c). Also, the very smooth coating with a roughness value of $296 \mathrm{~nm}$ is achieved by $\mathrm{SnCl}_{2}$ pre-flux (figure 3.d).
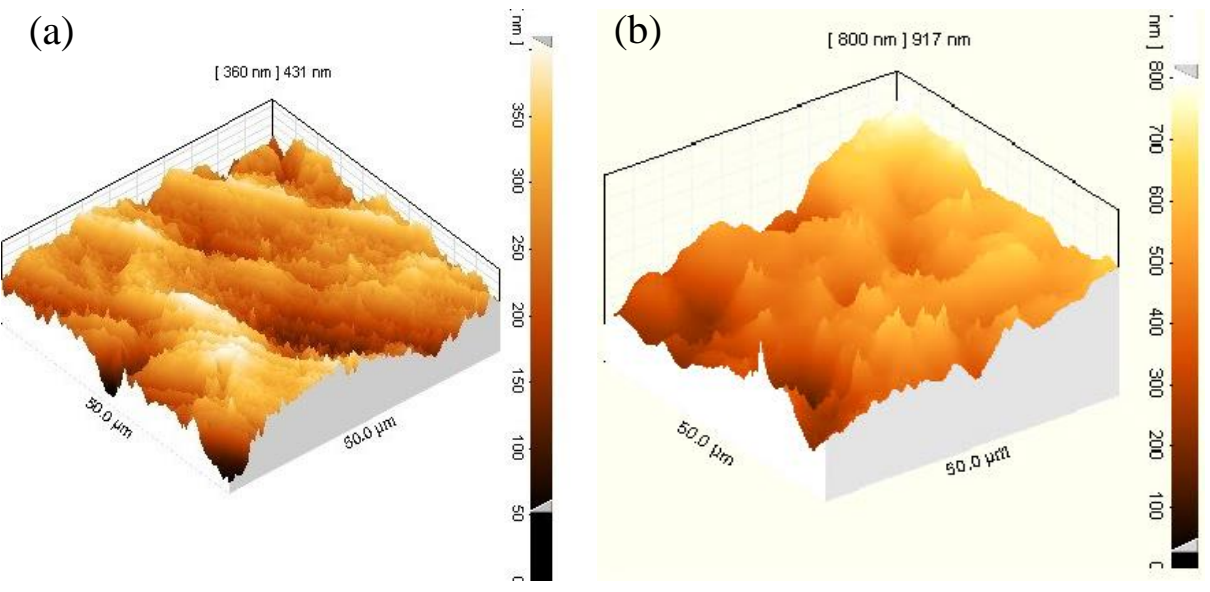


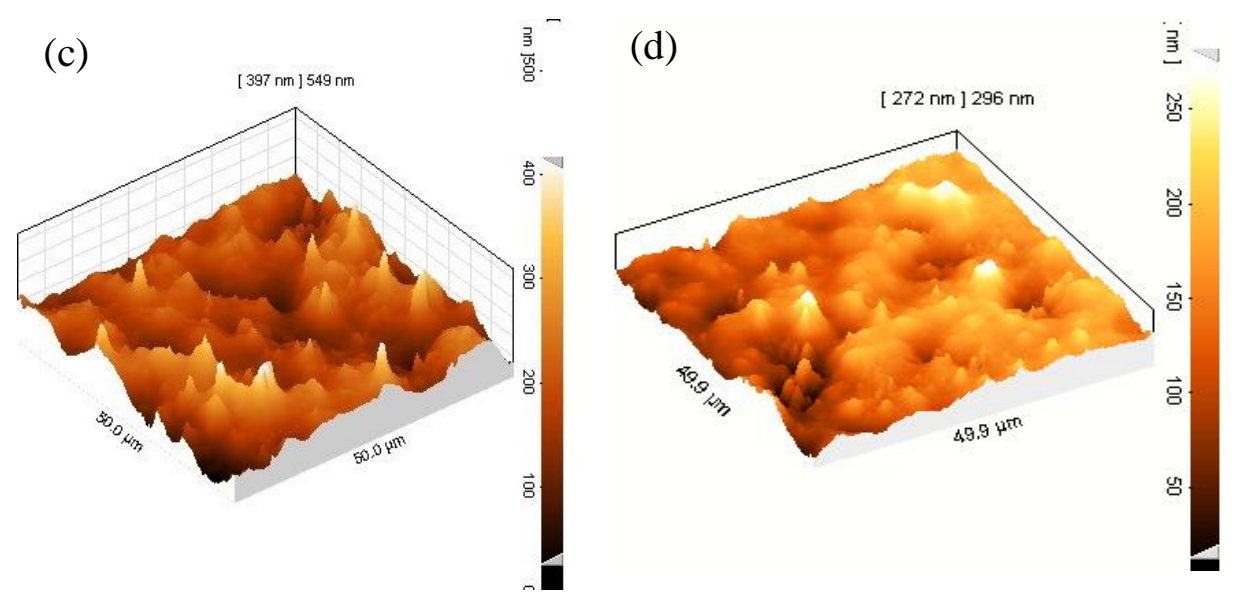

Fig. 3. The effect of pre-flux component on roughness value of the coating in different conditions: a) substrate, b) $\mathrm{ZnCl}_{2}$, c) $\mathrm{ZnCl}_{2}+\mathrm{SnCl}_{2}$ and d) $\mathrm{SnCl}_{2}$.

Therefore, it can be declared that the sufficient smooth coating of $\mathrm{Sn}-\mathrm{Sb}$ for $\alpha$ brass is achieved by $\mathrm{SnCl}_{2}$ pre-flux. In following the other parameters of the hot-dipping process, including bath temperature, exposure time and withdrawal speed of the specimen are investigated to optimize the coating process. The effect of these parameters on coating thickness was illustrated in figure 4 . In the case of bath temperature, it was obviously observed that by increasing bath temperature from 250 to $290^{\circ} \mathrm{C}$, the thickness of the promoted coating is increased. When the immersion temperature is increased to $300{ }^{\circ} \mathrm{C}$, the thickness of the developed coating was considerably decreased. Therefore, it can be demonstrated that the $290{ }^{\circ} \mathrm{C}$ is known as critical temperature for the hot dipping process of $\mathrm{Sn}$-Sb coating on the $\alpha$-brass alloy. By increasing temperature from a critical point, the promoted coating is expected to deflect. For instance, when the exposure time of the specimen is $10 \mathrm{sec}$ and it is withdrawn with the speed of $254 \mathrm{~mm} / \mathrm{min}$, the thickness of the obtained coating in bath temperatures of 250 and $290{ }^{\circ} \mathrm{C}$ are approximately 3 and $9 \mu \mathrm{m}$, respectively. By increasing bath temperature, similar variation about the obtained coating thickness was observed for other exposing time and the specimens' withdrawing speed. Also, it was obviously observed from figure 4 that when the immersion temperature and exposure time of the specimens are constant, increasing withdrawal speed leads to a considerable increase in the thickness of the coating. When the bath temperature is 250 ${ }^{\circ} \mathrm{C}$ and the specimens' immersion time is 10 seconds (figure 4.a), the thickness of the developed coating for withdrawal speed of $254 \mathrm{~mm} / \mathrm{min}$ and $1524 \mathrm{~mm} / \mathrm{min}$ is 3 and 15 $\mu \mathrm{m}$, respectively. Similar behavior about the effect of withdrawal speed on coating thickness of the Zinc layer was observed by Snoussi et al. [25]. According to their result, it was revealed that when the specimen's withdrawal speed is increased from 101.6 to $152.4 \mathrm{~mm} / \mathrm{min}$, the value of the deposited Zinc on the unit area is reached from 550 to $850 \mathrm{~g} / \mathrm{m}^{2}$. The other interesting phenomenon which was occurred is related to the immersion time. From the investigation of all the coating conditions it was revealed that at constant bath temperature and withdrawal speed, the effect of immersion time on the thickness of the coating is negligible. 
(a)

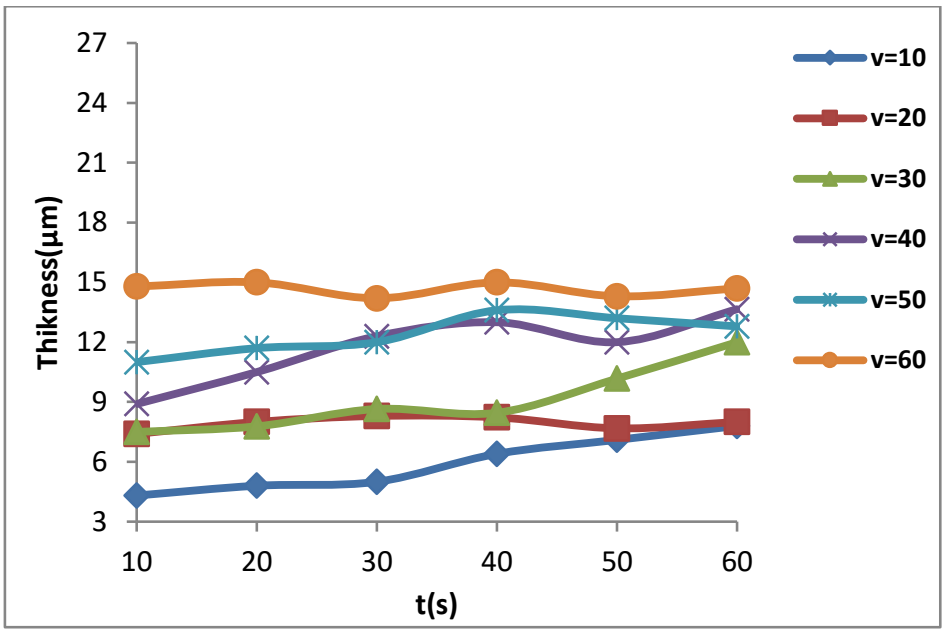

(b)

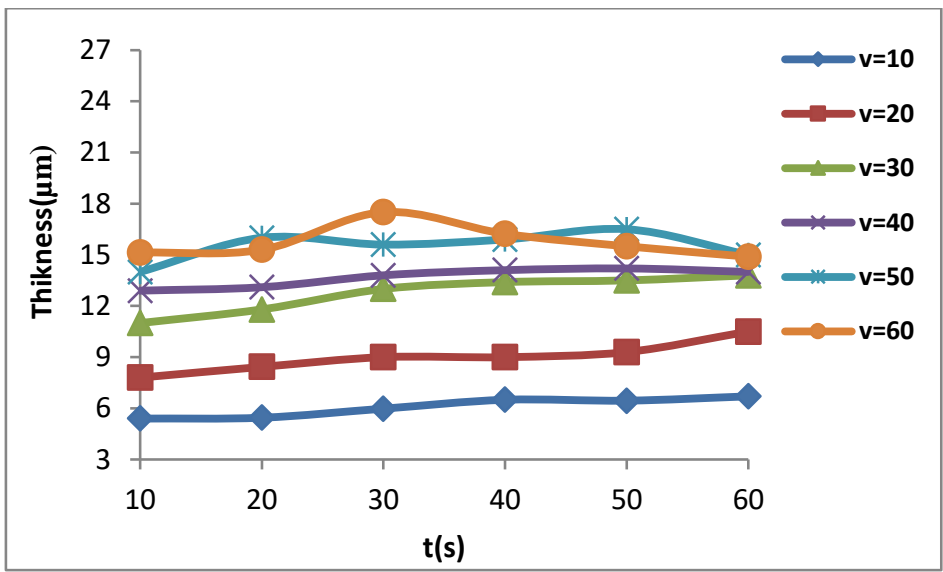

(c)

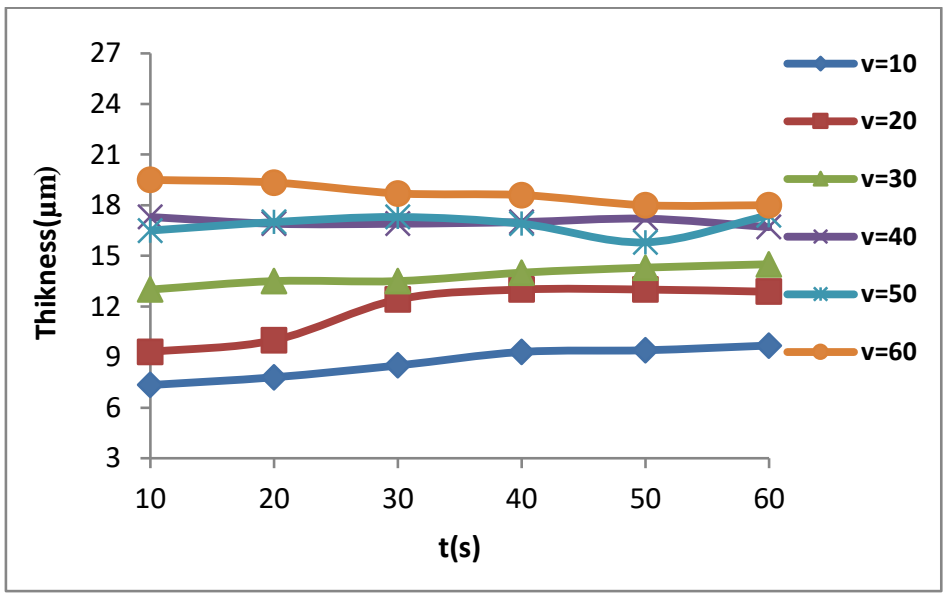


(d)

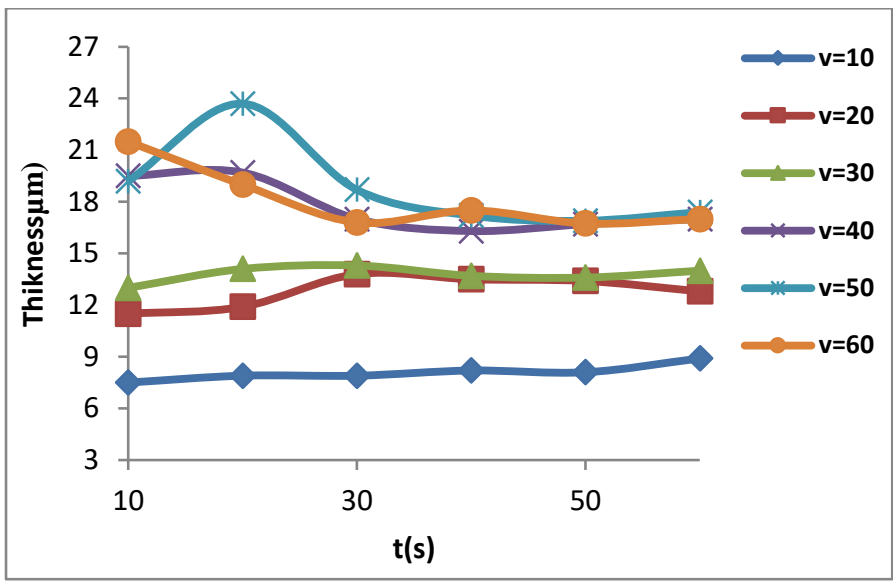

(e)

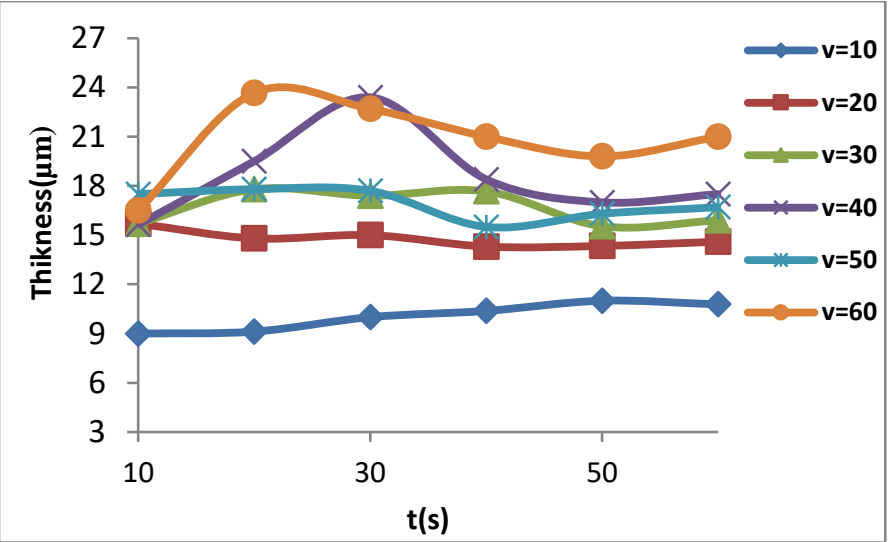

(f)

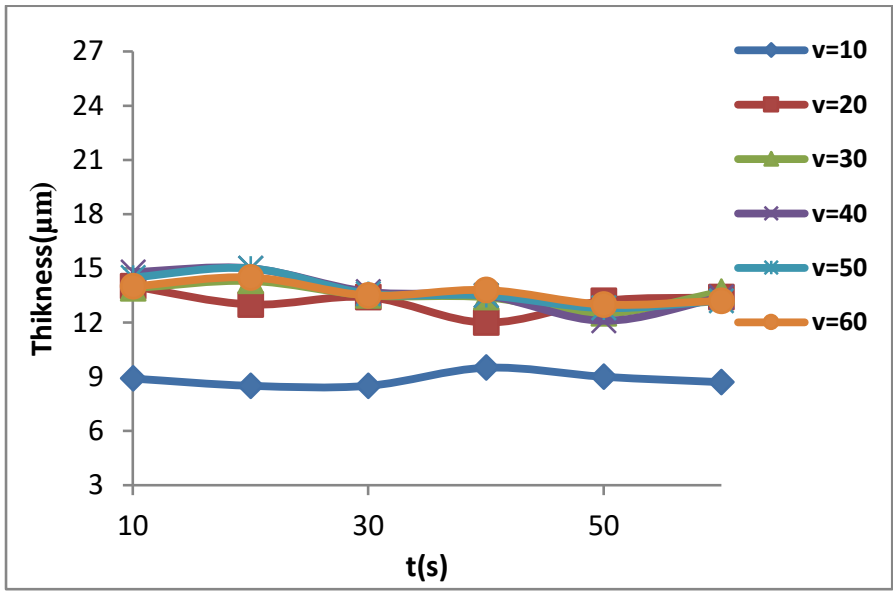

Fig. 4. The effect of exposure time and withdrawal speed of the specimens on thick variation of the $\mathrm{Sn}-\mathrm{Sb}$ coating at different immersion temperature:

a) $\left.\left.\left.250{ }^{\circ} \mathrm{C}, \mathrm{b}\right) 260^{\circ} \mathrm{C}, \mathrm{c}\right) 270{ }^{\circ} \mathrm{C}, \mathrm{d}\right) 280^{\circ} \mathrm{C}$, e) $290{ }^{\circ} \mathrm{C}$, and f) $300{ }^{\circ} \mathrm{C}$. 
For instance, when the bath temperature and withdrawal speed of the specimens is 280 and $254 \mathrm{~mm} / \mathrm{min}$ (figure 4.d), by increasing the immersion time from 10 to 60 seconds the thickness of the promoted coating is approximately increased from $7 \mu \mathrm{m}$ to $9 \mu \mathrm{m}$. The difference between the thickness of the coating by increasing immersion time for other specimens is inconsiderable. Therefore, it can be declared that immersion time has a more negligible effect on the thickness of coating in comparison with bath temperature and withdrawal speed.

In following the quality of the obtained coatings was evaluated using optical microscopy. The result revealed that when the immersion temperature is in the range of 260-290 ${ }^{\circ} \mathrm{C}$ and the exposing time and withdrawal speed are in the range of 10-30 seconds and $508-1016 \mathrm{~mm} / \mathrm{min}$, sufficient coating is achieved. The microstructure of the developed coating in optimal condition was illustrated in figure 5.

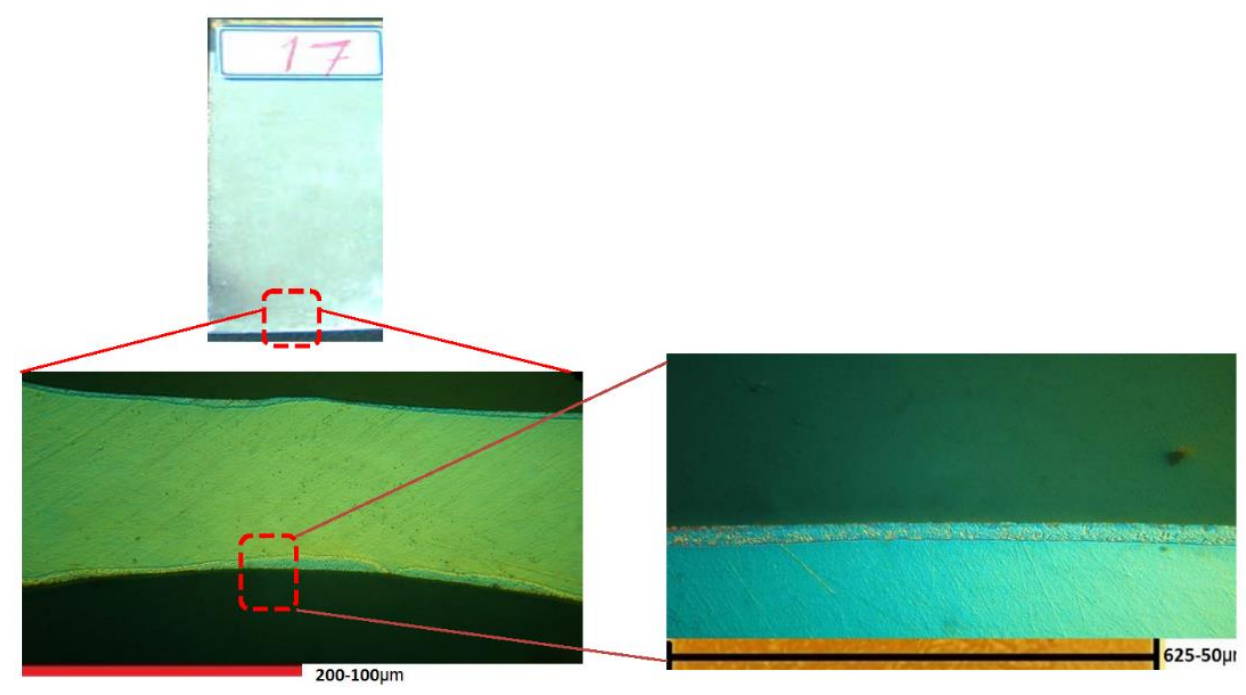

Fig. 5. The optical microstructure of the $S n-2.5 \%$ Sb coating for $\alpha$-brass alloy at optimal hot dipping condition: bath temperature: $260{ }^{\circ} \mathrm{C}$, immersion time: $10 \mathrm{~s}$, withdrawal speed: $762 \mathrm{~mm} / \mathrm{min}$.

$X R D$ and SEM analysis of the coating and substrate

It was obviously observed that the best appearance of the coating is achieved by using $\mathrm{SnCl}_{2}$ pre-flux. In the following, the effect of batch temperature on the evolution of phases was investigated. The result of low angle XRD analysis of the specimens, which was coated at the bath temperature of 260 and $290{ }^{\circ} \mathrm{C}$ has been illustrated in figure 6.a and figure $6 . b$, respectively.

The intermetallic compounds $\mathrm{Cu}_{3} \mathrm{Sn}$ and $\mathrm{Cu}_{6} \mathrm{Sn}_{5}$ have been characterized via XRD analysis. These phases have been developed at the interface of the substrate (brass alloy) and coating $(\mathrm{Sn}-\mathrm{Sb})$. The result revealed that by increasing the bath temperature, the intensity of the $\mathrm{Cu}_{3} \mathrm{Sn}$ phase has been augmented. The evolution of $\mathrm{Cu}_{3} \mathrm{Sn}$ and $\mathrm{Cu}_{6} \mathrm{Sn}_{5}$ phases on $\mathrm{Cu}-\mathrm{Sn}$ coating was previously observed by Silva et al. [26-29]. The experimental observation revealed that during nucleation and growth of $\mathrm{Cu}-\mathrm{Sn}$ phases, the first phase which is appeared near to the interface is $\mathrm{Cu}_{3} \mathrm{Sn}$ followed by $\mathrm{Cu}_{6} \mathrm{Sn}_{5}$. Park 
et al. [30] simulated the nucleation and growth of these phases in the $\mathrm{Cu}-\mathrm{Sn}$ system by multiphase model. According to their result, it was declared that the $\mathrm{Cu}_{3} \mathrm{Sn}$ phase is nucleated near to the interface. A similar result is observed in our experimental evaluation. According to SEM observation (figure 7.a), it was obviously revealed that $\mathrm{Cu}_{3} \mathrm{Sn}$ and $\mathrm{Cu}_{6} \mathrm{Sn}_{5}$ are promoted continually. The line scan analysis from the coating surface to the substrate region is illustrated in figure 7.b; the result revealed that the concentration of the $\mathrm{Sn}$ and $\mathrm{Sb}$ elements are constant at the coating region. By entering the substrate region, the concentration of $\mathrm{Cu}$ and $\mathrm{Zn}$ elements was sharply decreased.
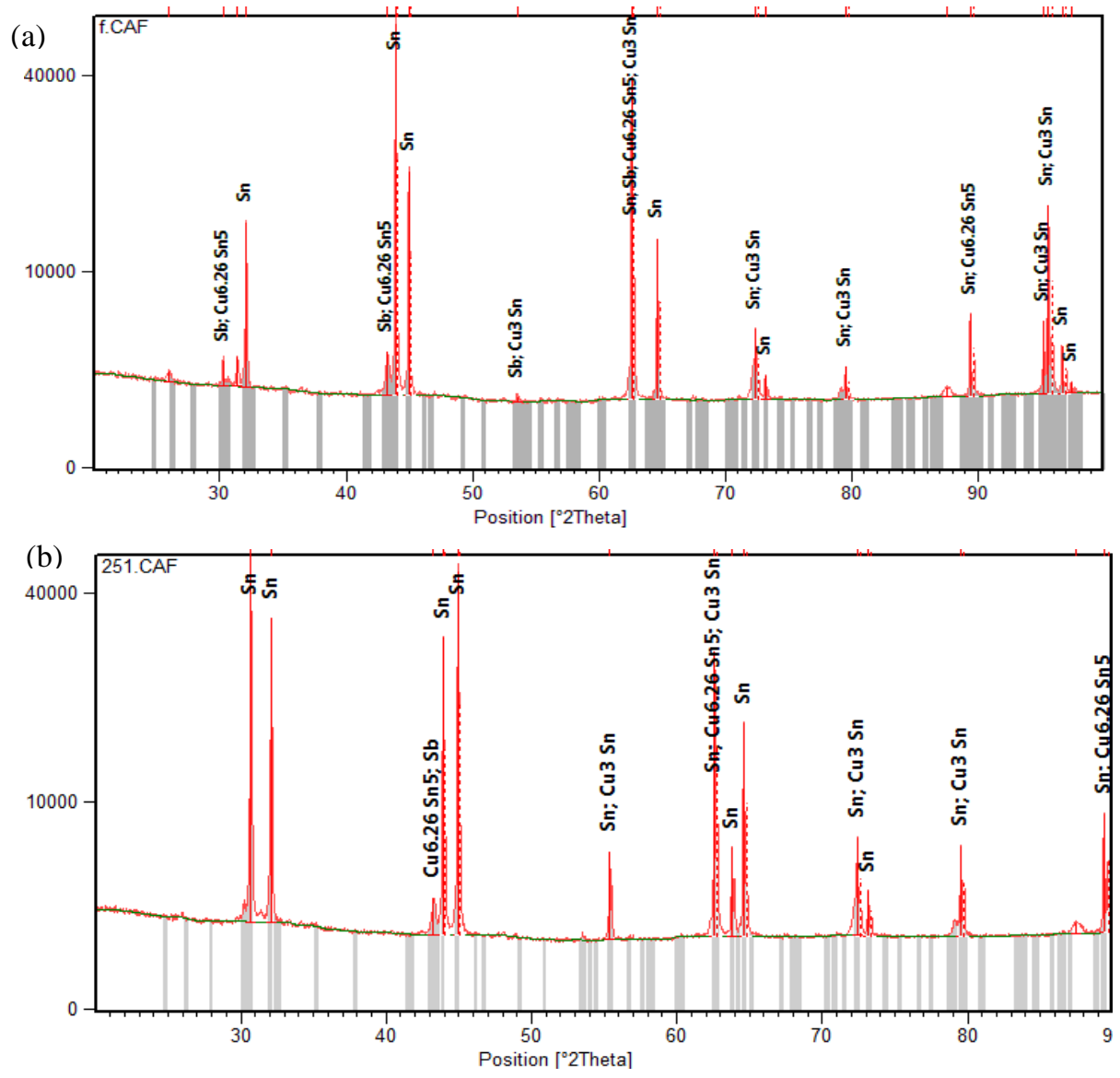

Fig. 6. The effect of immersion temperature on XRD pattern of the Sn-2.5\% Sb coating: a) $260{ }^{\circ} \mathrm{C}$, b) $290{ }^{\circ} \mathrm{C}$. 
(a)

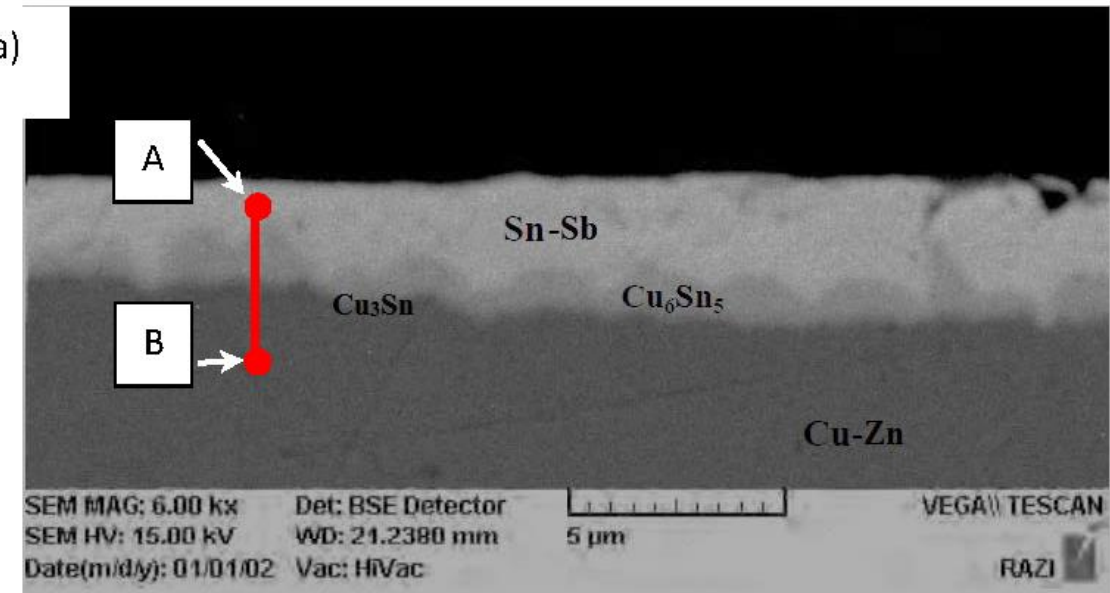

(b)

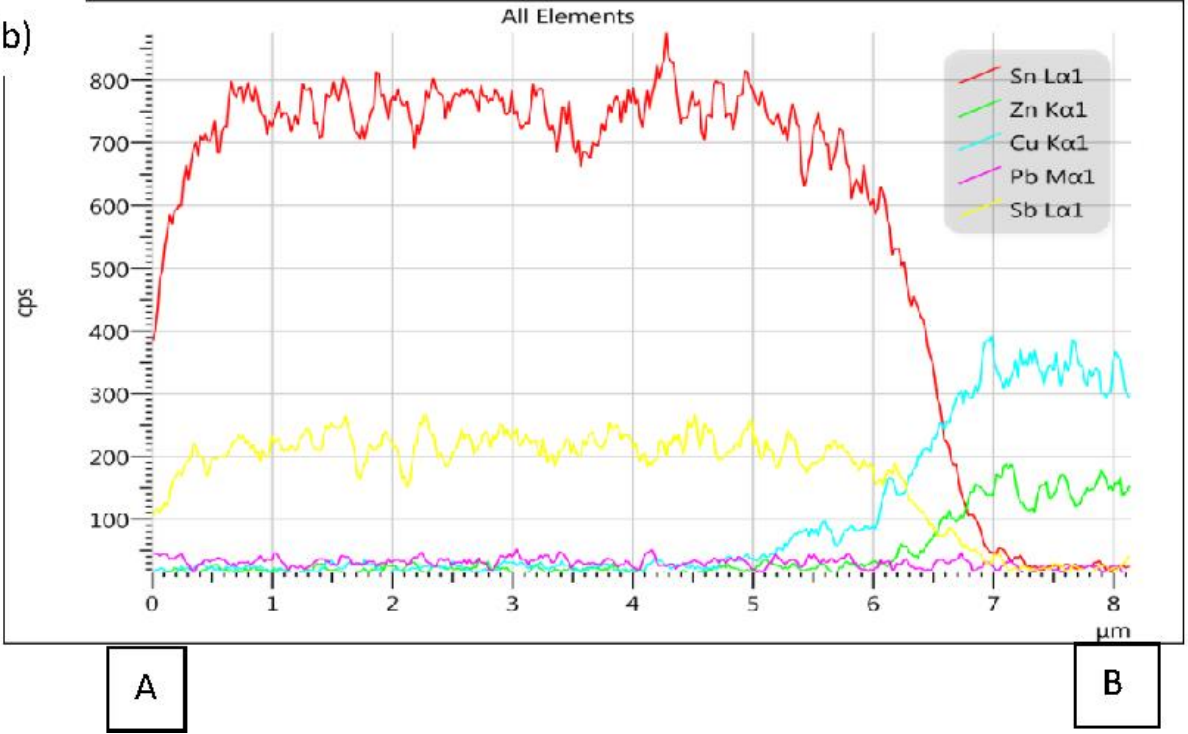

Fig. 7. SEM image of the substrate ( $\mathrm{Cu}-\mathrm{Zn})$ and coating ( $\mathrm{Sn}-\mathrm{Sb})$ after hot dipping process at $290{ }^{\circ} \mathrm{C}$ and $\mathrm{SnCl} 2$ pre-flux additive: a) SEM, b) Line scan analysis.

The effect of pre-flux additive and immersion temperature on Corrosion behavior of specimens

In this section, the effects of various pre-flux additives and immersion temperature on the corrosion behavior of specimens were quantitatively evaluated. In figure 8.a the polarization curve of the $\alpha$-brass alloy without coating has been illustrated. It was observed that the active/passive transition had occurred at $-0.2 \mathrm{~V}$. As a result of the coating process, the passive region of the specimens has been shifted to the left part (i.e. lower applied potential). According to polarization curves, it was revealed that the immersion temperature and pre-flux additive have a significant effect on active/passive transition voltage. In the case of $\mathrm{SnCl}_{2}$ pre-flux, by increasing immersion temperature 
from 260 (figure 8.b) to $290{ }^{\circ} \mathrm{C}$ (figure 8.c), the active/passive transition voltage was approximately unchanged, and its value was $-0.38 \mathrm{~V}$. However, when the immersion temperature was $260{ }^{\circ} \mathrm{C}$, the active/passive transition voltage for $\mathrm{SnCl}_{2}$ (figure 8.b) and $\mathrm{SnCl}_{2}+\mathrm{ZnCl}_{2}$ (figure 8.d) pre-flux additives were -0.38 and $-0.43 \mathrm{~V}$, respectively. Therefore, it can be declared that the $\mathrm{SnCl}_{2}$ pre-flux has significantly improved the corrosion resistance of the specimen. According to the visual inspection (figure 1) and roughness measurement (figure 3), it was revealed that $\mathrm{SnCl}_{2}$ pre-flux is attributed to a more smooth coating. The quantitative analysis of the corrosion polarization test has been summarized in table 3 . The corrosion rate of the $\alpha$-brass alloy without coating (sample 1) is approximately $0.63316 \mathrm{~mm} /$ year. Similar to polarization curves (figure 8), Sn-2.5\% $\mathrm{Sb}$ coating leads to a noticeable increase in corrosion resistance of the specimens. The result revealed that the lowest corrosion rate (i.e. $0.051656 \mathrm{~mm} /$ year) is acquired when bath temperature is $290{ }^{\circ} \mathrm{C}$ and $\mathrm{SnCl}_{2}$ pre-flux additive is used via hot dipping process (sample 3). Although, the corrosion rate of sample 1 (pre-flux: $\mathrm{SnCl}_{2}, \mathrm{~T}=260{ }^{\circ} \mathrm{C}$ ) and sample 4 (pre-flux: $\mathrm{SnCl}_{2}+\mathrm{ZnCl}_{2}, \mathrm{~T}=260{ }^{\circ} \mathrm{C}$ ) is 0.084096 and $0.24201 \mathrm{~mm} /$ year, respectively. therefore, it can be concluded that the chemical composition of the pre-flux additive has a greater effect on the corrosion resistance of specimens in comparison with immersion temperature.

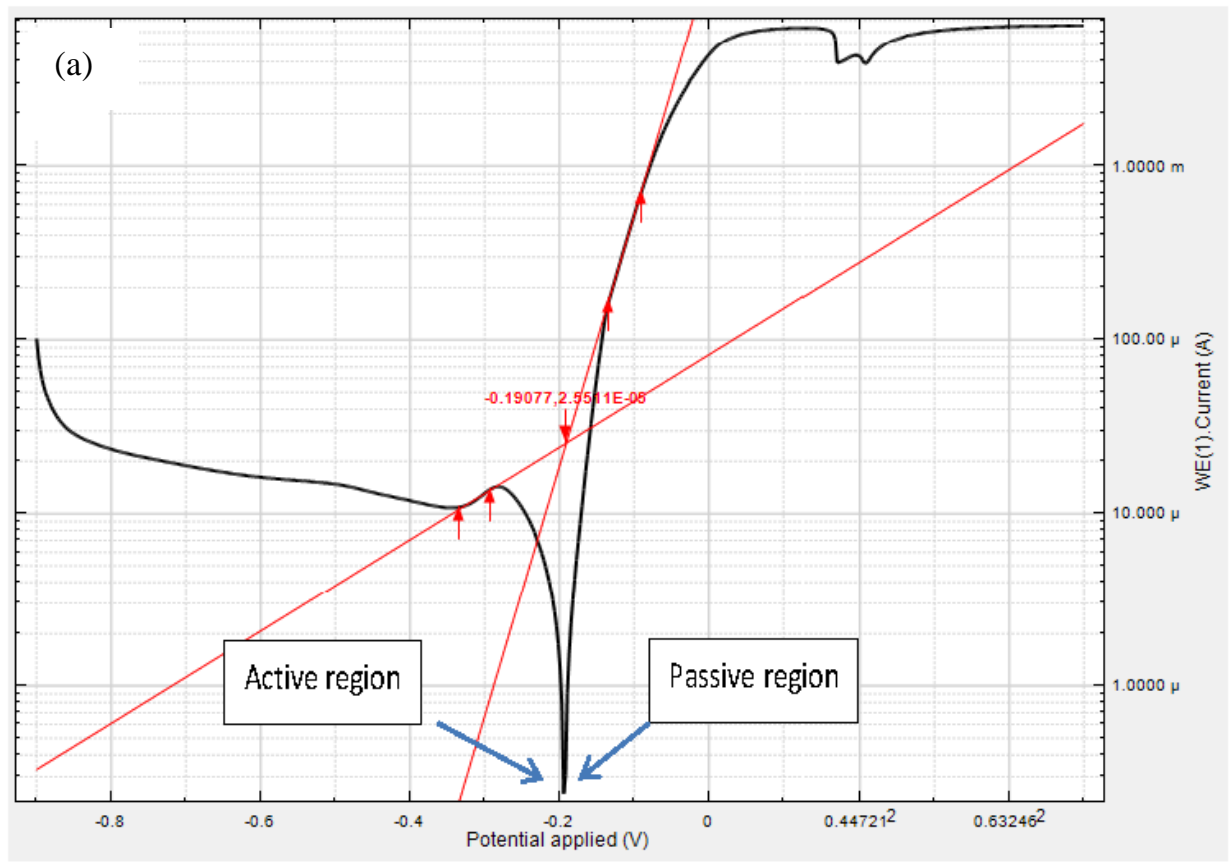



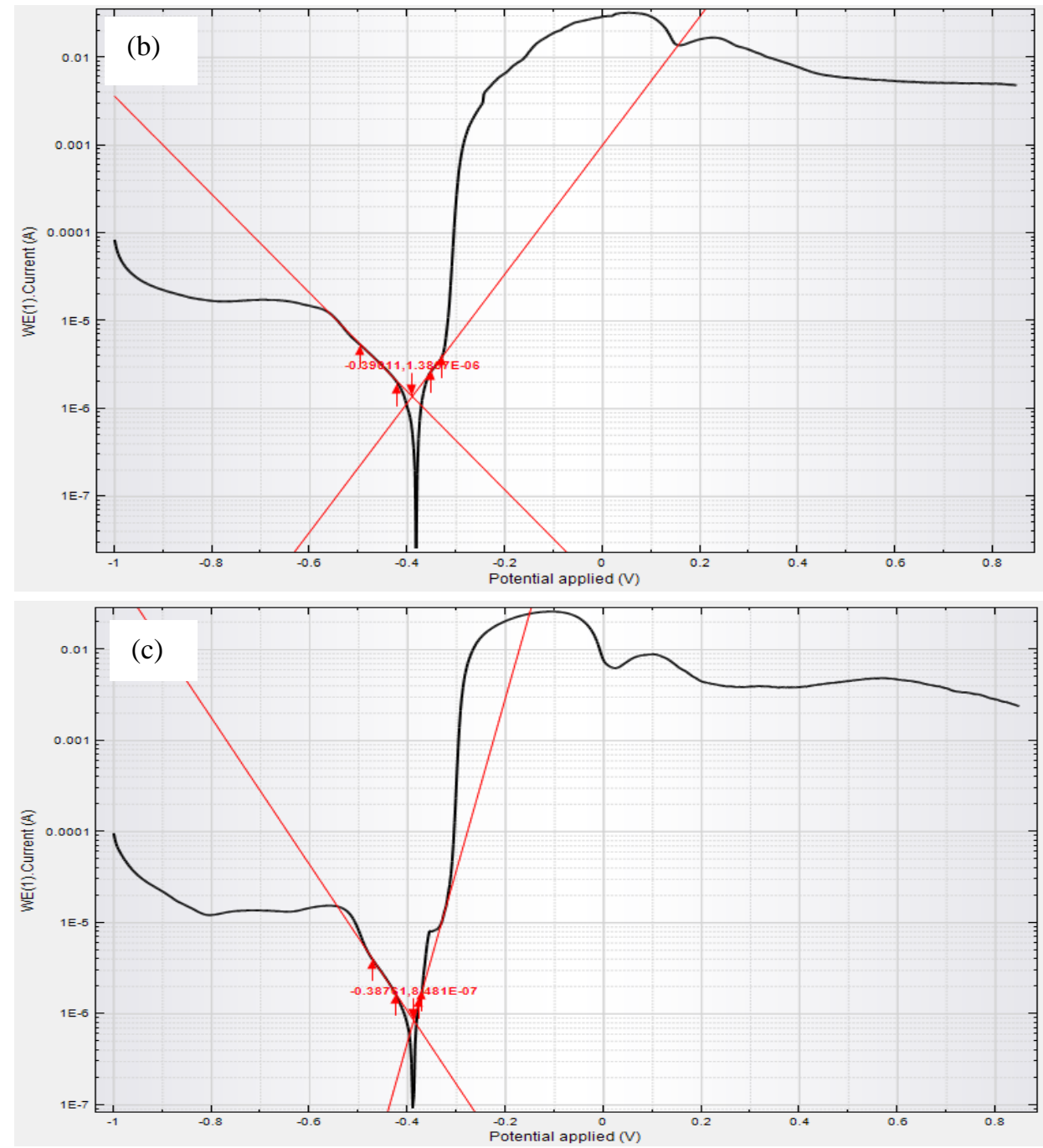


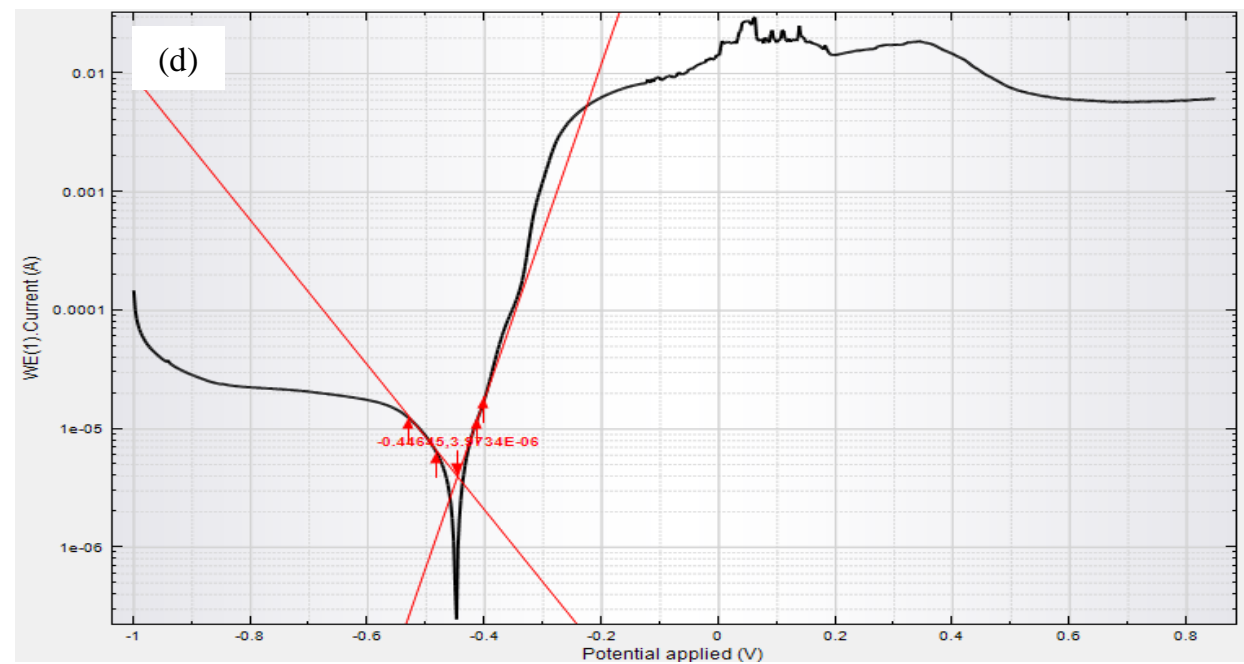

Fig. 8. Polarization curve of the specimens for investigating the effect of pre-flux additives and immersion time on corrosion behavior of the specimen: a) substrate, $b$ ) preflux additive: $\mathrm{SnCl}_{2}, \mathrm{~T}=260{ }^{\circ} \mathrm{C}$, c) pre-flux additive: $\mathrm{SnCl}_{2}, \mathrm{~T}=290{ }^{\circ} \mathrm{C}$, d) pre-flux additive: $\mathrm{SnCl}_{2}+\mathrm{ZnCl}_{2}, \mathrm{~T}=260{ }^{\circ} \mathrm{C}$.

Table 3. Quantitative analysis of corrosion behavior of specimens with various pre-flux additives.

\begin{tabular}{|c|c|c|c|c|c|}
\hline Sample & Pre-flux & $\begin{array}{l}\text { Immersion } \\
\text { temperature } \\
\left({ }^{\circ} \mathrm{C}\right)\end{array}$ & $\begin{array}{l}\text { Corrosion rate } \\
\text { (mm/year) }\end{array}$ & $\begin{array}{l}\text { Corrosion } \\
\text { current } \\
\text { density } \\
\left(\mu \mathrm{A} / \mathrm{cm}^{2}\right)\end{array}$ & $\begin{array}{l}\text { Corrosion } \\
\text { potential } \\
(\mathrm{mV})\end{array}$ \\
\hline ( $\alpha$-brass) & - & - & 0.63316 & 25.511 & -190.77 \\
\hline $\begin{array}{l}\text { Sample } \\
1\end{array}$ & $\mathrm{SnCl}_{2}$ & 260 & 0.084096 & 1.3807 & -390.11 \\
\hline $\begin{array}{l}\text { Sample } \\
2\end{array}$ & $\mathrm{SnCl}_{2}$ & 290 & 0.051656 & 0.8481 & -388.70 \\
\hline $\begin{array}{l}\text { Sample } \\
3\end{array}$ & $\begin{array}{l}\mathrm{SnCl}_{2}+ \\
\mathrm{ZnCl}_{2}\end{array}$ & 260 & 0.24201 & 3.9734 & -446.45 \\
\hline
\end{tabular}

According to the SEM result (figure 9) it was obviously observed that as a result of $\mathrm{SnCl}_{2}$ additive, coarse planar $\mathrm{Sn}$-Sb phases has been promoted on the surface of sample 3. Among the planar Sn-Sb phases, very fine cubic particles have been observed. These phases are the main reason for decreasing the corrosion rate of the $\mathrm{Sn}-\mathrm{Sb}$ coating. The XRD pattern of the corrosion product was illustrated in figure 10. For the meticulous investigation, the XRD patterns of the different components were separately derived. The result revealed that the predominant phase which is appeared after the corrosion test is $\mathrm{Sn}_{21} \mathrm{Cl}_{16}(\mathrm{OH})_{14} \mathrm{O}_{6}$ (figure 10.a). The surface of the interface was completely covered by this phase. Therefore, after coating annihilation during corrosion test, this phase has existed in the interface of $\alpha$-brass and $\mathrm{Sn}$-Sb coating. Furthermore, the corrosion resistance of the coated specimens is augmented as a result of this phase. In addition to 
$\mathrm{Sn}_{21} \mathrm{Cl}_{16}(\mathrm{OH})_{14} \mathrm{O}_{6}$ phase, the XRD result revealed that the other important phases like $\mathrm{SnO}$ and $\mathrm{SnO}_{2}$ (figure 10.b) and $\mathrm{SnCl}_{2}$ (figure 10.c) were developed via corrosion test at $3.5 \% \mathrm{NaCl}$ solution. In figure 11 the XRD pattern of the substrate after the corrosion test was illustrated. The result revealed that various intermetallic compounds including $\mathrm{Sn}_{21} \mathrm{Cl}_{16}(\mathrm{OH})_{14} \mathrm{O}_{6}, \mathrm{Cu}_{3} \mathrm{Sn}, \mathrm{CuCl}$, and $\mathrm{CuO}$ were promoted at the interface. Therefore, after coating annihilation during corrosion test, these appeared phases have been considerably restricted the corrosion rate.

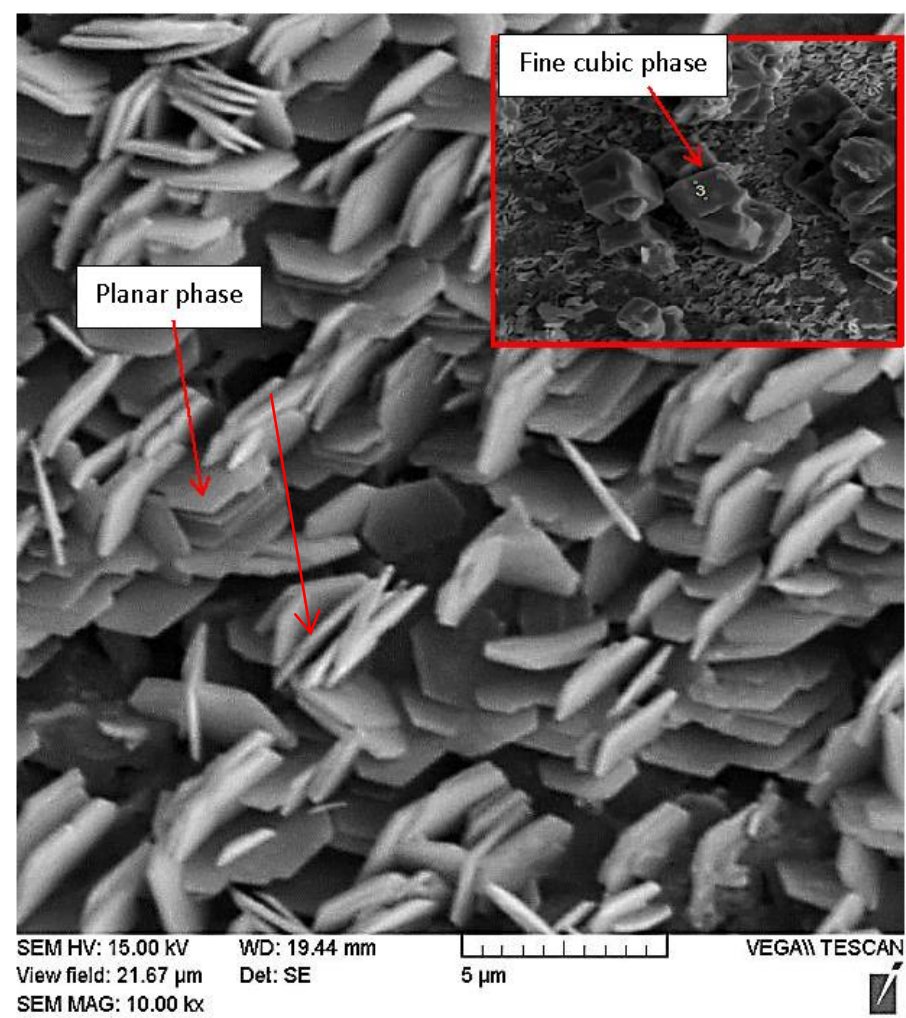

Fig. 9. SEM image of the Sn-2.5\% Sbcoating at optimized condition

(i.e. $T_{\text {immersion }}=290{ }^{\circ} \mathrm{C}$, $t_{\text {exposure }}=10$ seconds, $V_{\text {withdrawal }}=508 \mathrm{~mm} / \mathrm{min}$, pre-flux additive: $\mathrm{SnCl}_{2}$ ). 

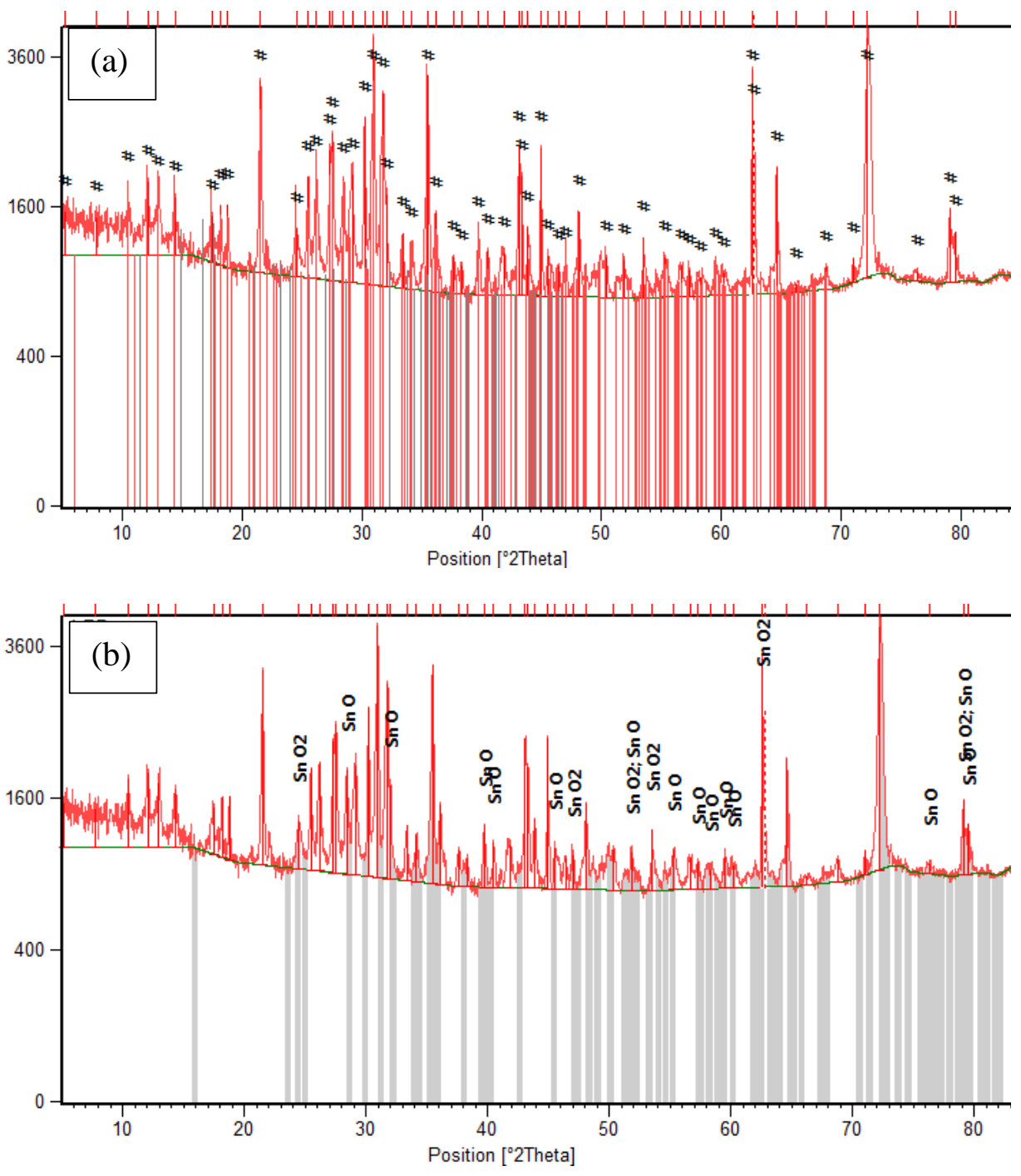


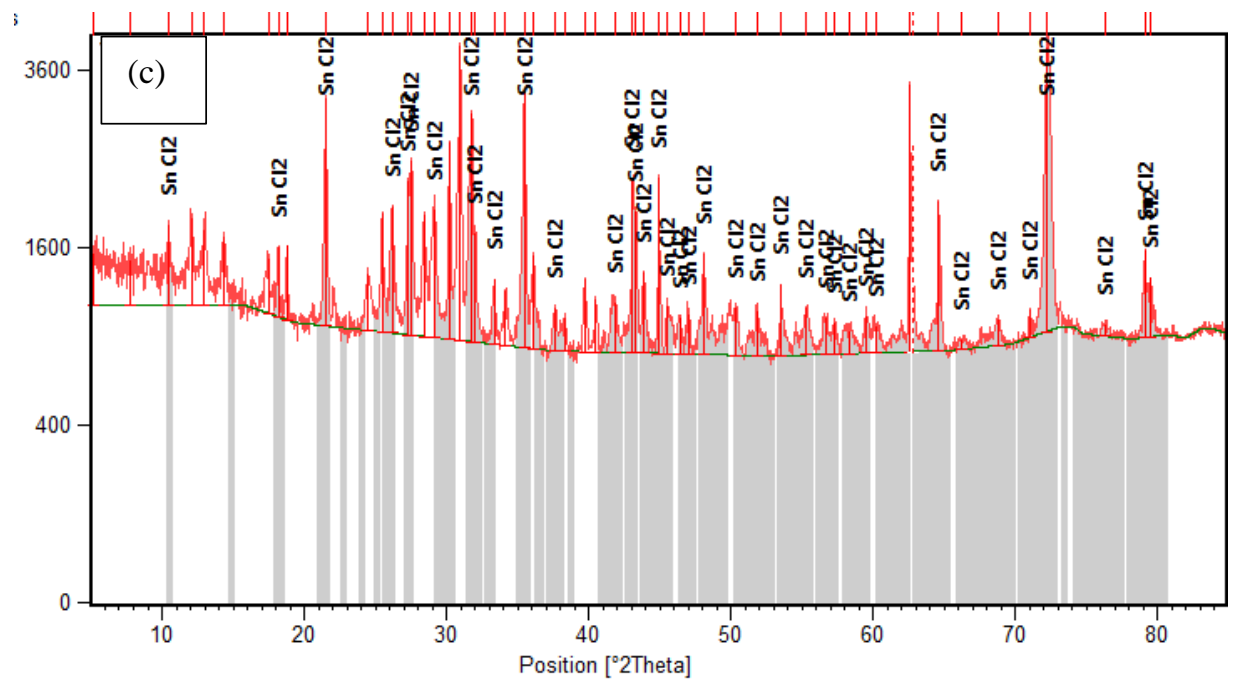

Fig. 10. XRD pattern of optimal coating of $S n-2.5 \%$ Sb for $\alpha$-brass after corrosion test: a) $\mathrm{Sn}_{21} \mathrm{Cl}_{16}(\mathrm{OH})_{14} \mathrm{O}_{6}$, b) $\mathrm{SnO}$ and $\mathrm{SnO}_{2}$, c) $\mathrm{SnCl}_{2}$ (for meticulous observation the peaks of the corrosion product component has been separated).

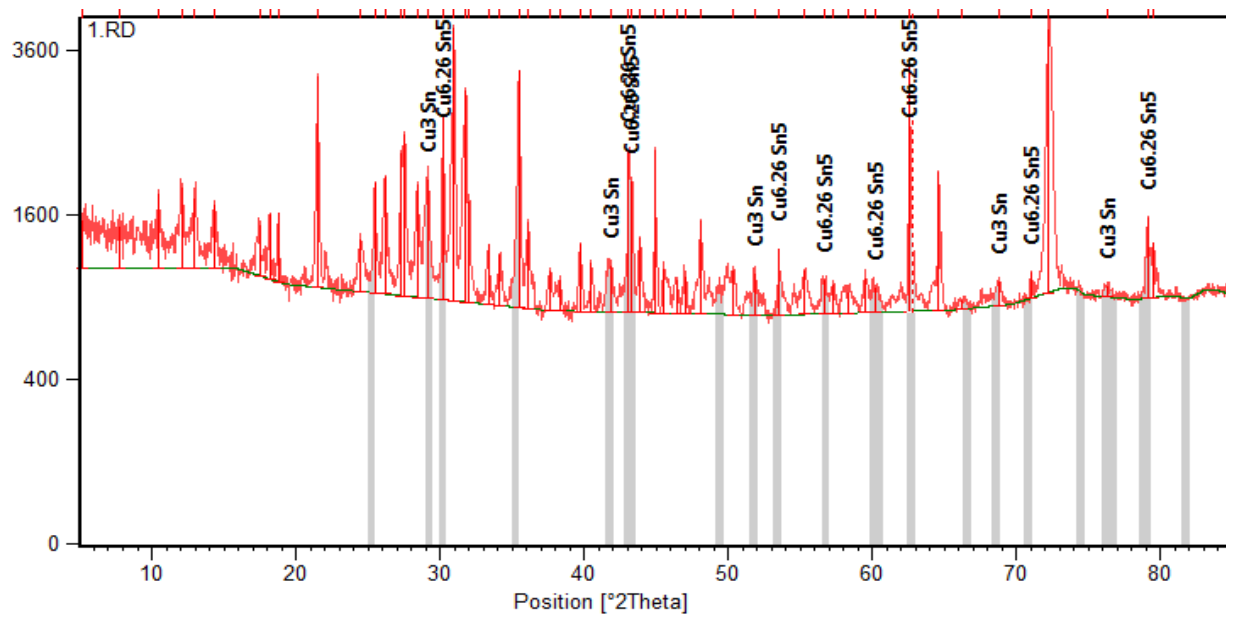




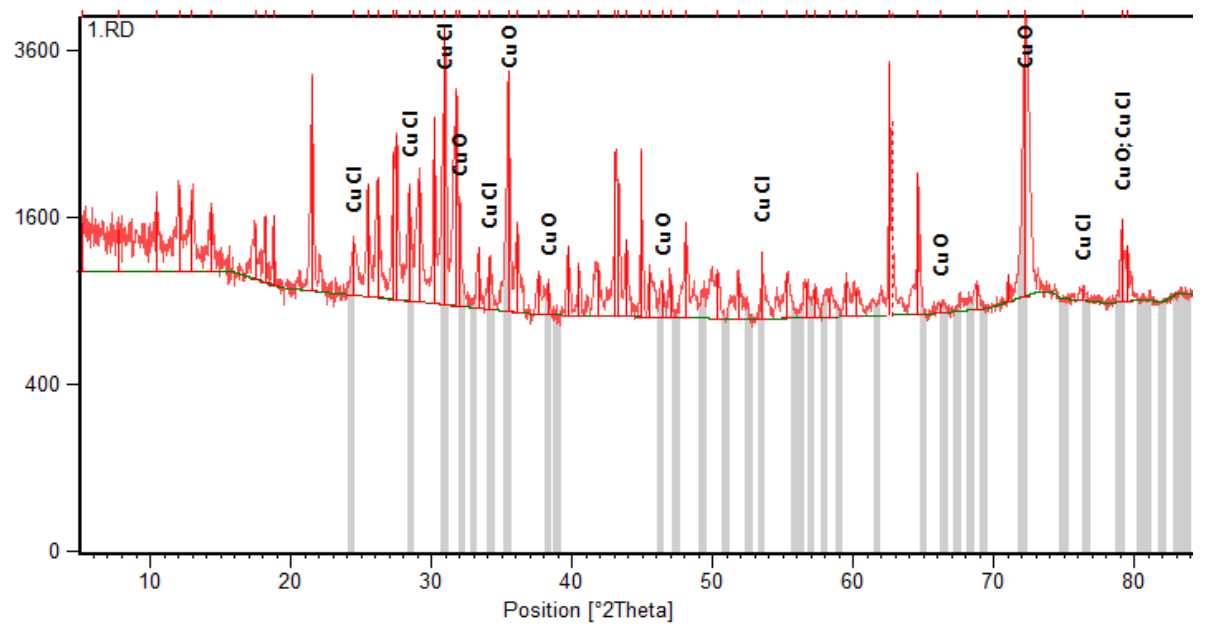

Fig. 11. XRD pattern of the substrate ( $\alpha$-brass) after corrosion test.

In figure 12, the SEM image of the appropriate coating at optimal condition was shown. The promotion of homogenous coating through the surface of the $\alpha$-brass alloy was obviously observed. Therefore, it can be concluded that the hot-dipping parameters have a significant effect on final coating quality. In the following, the main result of this research was briefly summarized.

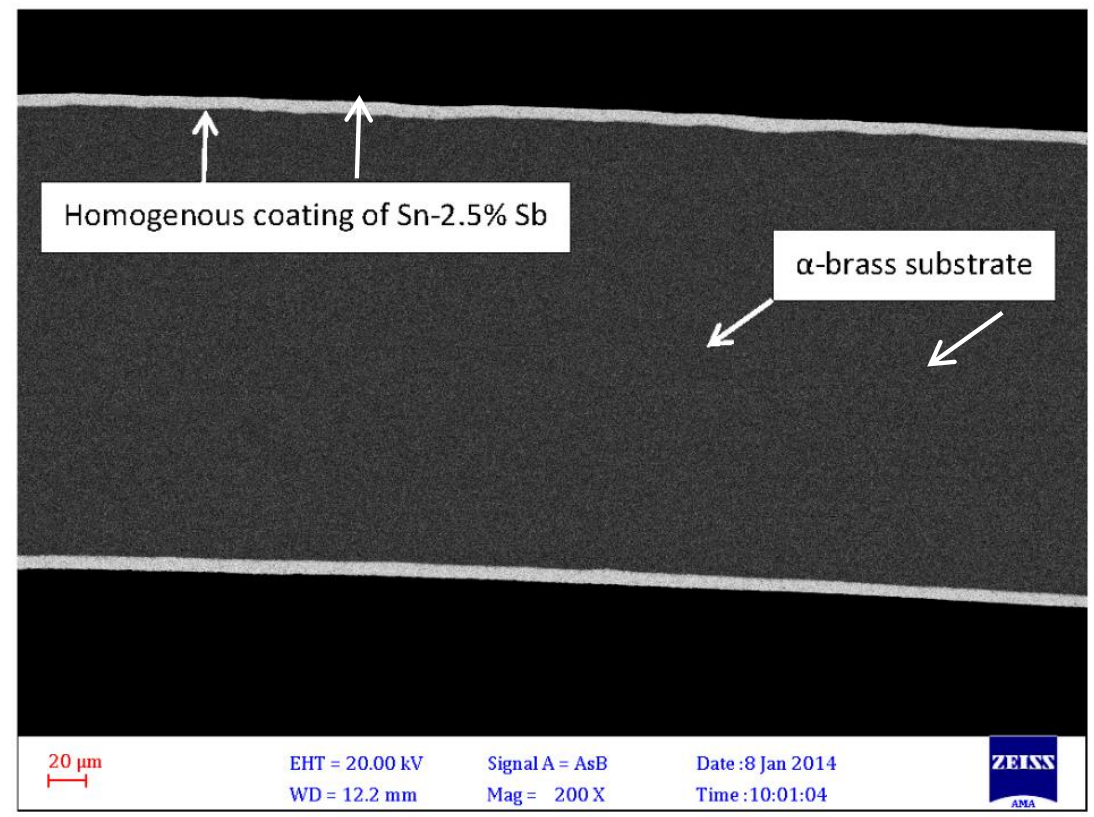

Fig. 12. achieving optimal coating of $S n-2.5 \%$ Sb for $\alpha$-brass by controlling hot dipping parameters. 


\section{Conclusion}

In this research, the hot-dip coating of $\mathrm{Sn}-2.5 \% \mathrm{Sb}$ for $\alpha$-brass was comprehensively investigated. After optimizing the hot-dipping process, the corrosion behavior of the various coating was analyzed. The main results can be concluded as follows:

- The effect of various pre-flux additives on coating quality was visually inspected. The result revealed that using pre-flux additive during the hot-dipping process of $\mathrm{Sn}-2.5 \% \mathrm{Sb}$ coating on $\alpha$ brass is required. Without using pre-flux additive, the coating process has not been appropriately fulfilled. AFM result revealed that uniform and the smooth coating is accomplished by using $\mathrm{SnCl}_{2}$ as a pre-flux additive.

- Withdrawal speed of the specimens and bath temperature has a significant effect on the thickness and uniformity of promoted coating. According to the microstructure evaluation, it was revealed that a uniform coating of $\mathrm{Sn}-2.5 \% \mathrm{Sb}$ for the $\alpha$-brass alloy is achieved when the bath temperature is in the range of $260-290{ }^{\circ} \mathrm{C}$ and the withdrawal speed of the specimens is in the range of 508$1016 \mathrm{~mm} / \mathrm{min}$.

- When the bath temperature and withdrawal speed of the specimens are constant, the effect of exposure time on the thickness of the coating is inconsiderable. However, the excellent coating is promoted when the exposure time of the specimens is in the range of 10-30 seconds.

- $\quad \mathrm{XRD}$ and SEM results revealed that during the hot dipping process, $\mathrm{Cu}_{3} \mathrm{Sn}$ and $\mathrm{Cu}_{6} \mathrm{Sn}_{5}$ are developed continually. $\mathrm{Cu}_{3} \mathrm{Sn}$ is the first phase that is nucleated; therefore, this phase is near to the substrate ( $\alpha$-brass). By increasing the bath temperature from 260 to $290{ }^{\circ} \mathrm{C}$ the intensity of these phases is increased. Also, the intensity of the $\mathrm{Cu}_{3} \mathrm{Sn}$ phase is more than $\mathrm{Cu}_{6} \mathrm{Sn}_{5}$ phase.

- According to the corrosion polarization test, the corrosion rate of the specimens was significantly decreased as a result of the coating process. The highest corrosion resistance is obtained by using $\mathrm{SnCl}_{2}$ as pre-flux additives. The formation of smooth coating with planar morphology is the main reason for this phenomenon.

- After investigating various coating parameters, it can be concluded that during the hot-dipping process of Sn- $2.5 \%$ Sn coating on $\alpha$-brass, the optimal condition is as follow: bath temperature $=290{ }^{\circ} \mathrm{C}$, exposing time: 10 seconds, withdrawal velocity: $508 \mathrm{~mm} / \mathrm{min}$ and pre-flux additive: $\mathrm{SnCl}_{2}$. 


\section{References}

[1] B. Hanane, H. Lgaz, M.E. Touhami, Y. Baymou, K. Seung-Hyun, C. Kwon, S.K. Park, Y. Hassani, I.M. Chung: Colloids. Surf. A, 606 (2020) 125399-125408.

[2] J. Ouassir, H. Bennis, H. Benqlilou, M. Galai, Y. Hassani, M.E. Touhami, K. Berrami,M. Lemyasser: Colloids Surf. Physicochem. Eng. Asp, 586 (2020) 124151-124163.

[3] M. Galai, J. choucri, Y. Hassani, H. Benqlilou, I. Mansouri, B. Ouaki, M. EbnTouhami, C. Monticelli, F. Zucchi: Chem. Data Collect, 19 (2019) 100171100177.

[4] I. Milošev, T.K. Mikić, M. Gaberšček: Electrochim. Acta, 52 (2006) 415-426.

[5] E. Sherif, M. Rabab, M. Khaled, A. Waheed: Electrochim. Acta, 49 (2004) 51395150 .

[6] I.K. Marshakov: Prot. Met, 41 (2005) 205-210.

[7] B. Assouli, A. Srhiri, H. Idrissi: NDT E Int. 36 (2003) 117-126.

[8] F. Altaf, R. Qureshi, A. Yaqub, S. Ahmed: Chem. Pap, 73 (2019) 1221-1235.

[9] G. Kilinççeker: Colloids Surf. Physicochem. Eng. Asp, 329 (2008) 112-118.

[10] G. Chiara, M. Pascucci, C. Riccucci, E. Messina, M. Salzano, M. Lavorgna, G.M. Ingo, G.D. Carlo: Prog. Org. Coat. 122 (2018) 138-146.

[11] Maaß, Peter, Peter Peißker, Handbook of hot-dip galvanization, John Wiley \& Sons, New York, 2011, 165-171.

[12] S. Sepper, P. Peetsalu, M. Saarna: Agron. Res, 9 (2011) 229-236.

[13] K.W. Shinato, A.A. Zewde, Y. Jin: Corros. Rev, 38 (2020) 101-109.

[14] F. Hanna, N. Nassif: Surf. Coat. Technol, 21 (1984) 27-37.

[15] O.S. Bondareva, A.A. Melnikov: Key Eng. Mater, 685 (2016) 380-384.

[16] B.D. Deshmukh, A. P. Patil: Int. j. adv. res. Technol, 2 (2012) 71-75.

[17] O.R. Adetunji: J NAT GAS SCI ENG, 9 (2010) 23-31.

[18] S.Y. Sirin: Int. J. Fatigue, 123 (2019) 1-9.

[19] D.P. Pratim, P. Modak, A. Ghosh, D. Chakrabarti, P.S. Banerjee, M. Ghosh: Results in Materials, 6 (2020) 100078-100083.

[20] J.K. Chang, C.S. Lin, W.R. Wang, S. Jian: Appl. Surf. Sci, 511 (2020) 145550145557.

[21] W. Wang, D. Wang, F. Han: Mater. Lett, 248 (2019) 60-64.

[22] S.C. Jeng: Surf. Coat. Tech, 235 (2013) 867-874.

[23] C.J. Wang, S.M. Chen: Surf. Coat. Tech, 201 (2006) 3862-3866.

[24] J. Zang, P. Song, J. Feng, X. Xiong, R. Chen, G. Liu, J. Lu: Corros. Sci, 112 (2016) 170-179.

[25] A. Snoussi, C. Bradai, F. Halouani: Mater. Lett, 62 (2008) 2150-2152.

[26] P.S. Silva, L. Ferreira, D.B. DoLago: Mater. Res, 20 (2017) 667-675.

[27] Y. Wu, J.A. Sees, C. Pouraghabagher, L.A. Foster, J.L. Marshall, E.G. Jacobs, R.F. Pinizzotto, Mater, 22 (1993) 769-777.

[28] D.R. Frear, P.T. Vianco: Metall Mater Trans A, 25 (1994) 1509-1523.

[29] S. Bader, W. Gust, H. Hieber: Acta. Metal. Mater, 43 (1995) 329-337.

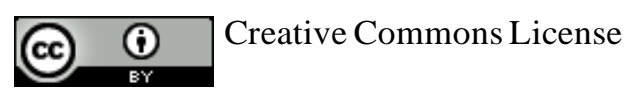

This work is licensed under a Creative Commons Attribution 4.0 International License. 